\title{
Identification of skin-expressed genes possibly associated with wool growth regulation of Aohan fine wool sheep
}

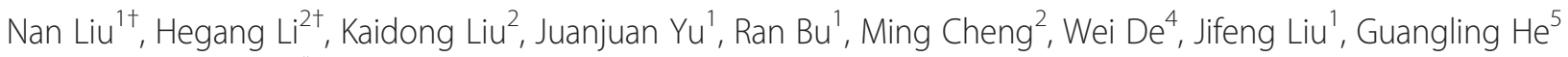
and Jinshan Zhao ${ }^{1,2,3^{*}}$

\begin{abstract}
Background: Sheep are valuable resources for the animal fibre industry. Therefore, identifying genes which regulate wool growth would offer strategies for improving the quality of fine wool. In this study, we employed Agilent sheep gene expression microarray and proteomic technology to compare the gene expression patterns of the body side (hair-rich) and groin (hairless) skins of Aohan fine wool sheep (a Chinese indigenous breed).

Results: Comparing the body side to the groin skins ( $\mathrm{S} / \mathrm{G}$ ) of Aohan fine wool sheep, the microarray study revealed that 1494 probes were differentially expressed, including 602 more highly expressed and 892 less highly expressed probes. The microarray results were verified by means of quantitative PCR. Cluster analysis could distinguish the body side skin and the groin skin. Based on the Database for Annotation, Visualization and Integrated Discovery (DAVID), 38 of the differentially expressed genes were classified into four categories, namely regulation of receptor binding, multicellular organismal process, protein binding and macromolecular complex. Proteomic study revealed that 187 protein spots showed significant $(p<0.05)$ differences in their respective expression levels. Among them, 46 protein entries were further identified by MALDI-TOF/MS analyses.

Conclusions: Microarray analysis revealed thousands of differentially expressed genes, many of which were possibly associated with wool growth. Several potential gene families might participate in hair growth regulation. Proteomic analysis also indentified hundreds of differentially expressed proteins.
\end{abstract}

Keywords: Microarray, Proteomic technology, Wool growth, Differential expression

\section{Background}

Sheep are valuable resources for the animal fibre industry. Identifying genes which regulate wool growth offers the opportunity to improve the wool production efficiency, product quality and diversity in breeding programs. It can also offer the opportunity to develop transgenic lines and to develop therapeutic agents that can be used to tailor for desirable fibre attributes by altering gene expression [1]. The genetic polymorphisms and their mechanisms of wool and cashmere growth and regulation have been thoroughly studied [1-5]. In mammals, several gene families,

\footnotetext{
* Correspondence: zhaojinshande@sohu.com

${ }^{\dagger}$ Equal contributors

'Qingdao Agricultural University, Qingdao 266109, China

${ }^{2}$ Qingdao Institute of Animal Science and Veterinary Medicine, Qingdao 266100, China

Full list of author information is available at the end of the article
}

such as WNTs, tumor necrosis factors (TNFs), fibroblast growth factors (FGFs) and transforming growth factor (TGFs), have been implicated in hair follicle initiation, morphogenesis and cycling [6,7]. Recently, the molecular characteristics of primary wool follicle initiation in Merino sheep have been reported recently [8].

Transcriptomic research such as microarray analysis, has been successfully applied to investigate the characteristics of hair follicle stem cells in mice [9-12]. Microarray studies have been reported for different traits in sheep and goats, such as resistance to parasites [13,14], mammary development and milk quality [15-17], wool follicle development [18], natural fleece rot resistance [19] and pigmentation traits of skin and wool [20]. A subset of skin-expressed microRNAs with possible roles in goat and sheep hair growth has also been reported 
[21]. Several studies have demonstrated the usefulness of cDNA microarray for expression profiling of wool follicle growth cycles in whole skin [22-24]. More recently the RNA-seq method was also used to determine the genes differentially expressed among various tissues (including whole skin) of sheep [25].

The Aohan fine wool sheep, bred in Inner Mongolia, is an outstanding breed, providing both wool and meat. The major characteristics of this breed are high quality wool, high disease resistance, and high adaptability. According to figures, Aohan fine wool sheep can provide up to $9 \mathrm{~kg}$ of quality wool per year (fiber length up to $10.5 \mathrm{~cm}$, fibre diameter less than $22 \mu \mathrm{m}$ ). Therefore, Aohan fine wool sheep are considered as a valuable genetic resource for fine wool production. Wang et al. demonstrated that seasonal factors significantly influenced the wool growth of Aohan fine wool sheep [26]. The peak of the growth rate occurs in summer and the low in winter [26]. The expression profiling of immune genes and type I inner root sheath (IRS) keratin genes in the whole skin of Aohan fine wool sheep has previously been reported by our laboratory team $[27,28]$.

However, to our knowledge, as of yet no microarray or proteomic study at a genome-wide level has been reported on protein-coding genes which are possibly responsible for regulating hair growth of adult sheep so far. The aims of the present work are to investigate and compare the gene expression level of the body side skin and groin skin using microarray and proteomic technology, and to identify the possible genes and proteins responsible for the wool growth regulation of Aohan fine wool sheep.

\section{Results}

\section{Summary of microarray analysis}

A total of 1494 probes were differentially expressed comparing the body side to groin skins (S/G) in Aohan fine wool sheep, including 602 up-regulated and 892 down-regulated probes, as shown in Additional file 1: Table S1. Most probes (1110) were not assigned to unique transcripts, due to the lack of information. The number of distinct genes/transcripts (annotated) was 331, of which 112 were up-regulated and 219 were down-regulated. In S/G, 7 genes (CYP1A1, LOC100137068, LOC443300, LOC101106865, Connexin 43, SCD and LOC101122398) were down-regulated by more than 10 -fold.

Furthermore, many gene families which regulate different aspects of hair follicle growth showed differential expression in S/G (see Additional file 2: Table S3), such as growth factors, immune cytokines, Keratins (KRT) and Keratin-associated proteins (KAP), and so on.

\section{Selective verification for microarray data by QPCR}

In order to verify the microarray results, we selected 10 genes, namely FGF10, LOC443300, FGF18, Connexin43,
SCD, ZO1, MMP2, ITGB1, PAG11 and CRYAB, to comparatively analyze their expression patterns by qPCR. As shown in Figure 1, the qPCR results for the selected seven genes were consistent with the microarray results, except for FGF10, ZO1 and CRYAB, thus reflecting the reliability of our microarray data.

\section{Hierarchical cluster analysis, biological process gene ontology (GO) analyses and putative gene networks}

To further investigate the similarity in the expression patterns of protein-coding genes between the two skin areas, we performed cluster analysis using the Cluster 3.0 tool. As shown in Figure 2, cluster analysis could make a distinction between the body side skin and the groin skin.

Based on the Database for Annotation, Visualization and Integrated Discovery (DAVID), 38 of the differentially expressed genes were classified into four categories, many of which shared the same genes, according to their functional correlation (Additional file 3: Table S2). The majority of the genes possibly related to the wool growth control could be assigned into four categories including regulation of receptor binding, multicellular organismal process, protein binding and macromolecular complex.

Two singnaling pathways, PI3K-AKT pathway and JAK-STAT pathway, were identified as biological pathways having more differentially expressed genes. Figure 3 displayed the putative interactions related to the differentially expressed genes of the two pathways. These interactions were intensively involved in cell cycle and apoptosis processes.

We speculate that wool growth regulation shared similar gene networks with hair. So particular differentially expressed genes, which also appeared in the conclusion of factors with known hair growth regulatory roles [29], were included in the putative gene lists of wool growth regulation (Figure 4). In the networks, 3 genes (FGF7, IGFBP3 and PRL) were contained in the category of anagen promotion and maintenance, 3 genes (IL1A, IL6 and TAC1) were contained in the category of catagen-telogen promotion and maintenance, while 2 genes (CDKN1B and FGF18) were contained in the category of function unknown.

\section{Quantitative comparison and identification of protein spots on 2-DE gels}

To detect differential protein expression between the two skin areas, we constructed triplicate $2 \mathrm{D}$ maps of protein samples for each group were created. Figure 5 shows two representative 2-DE gel images of the protein expression patterns of the two groups. One hundred and eighty-seven protein spots showed significant $(\mathrm{p}<0.05, t$-test) differences in expression levels between the body side skin group and the control. Of the 187, 85 protein spots were more highly expressed and 102 were less highly expressed 


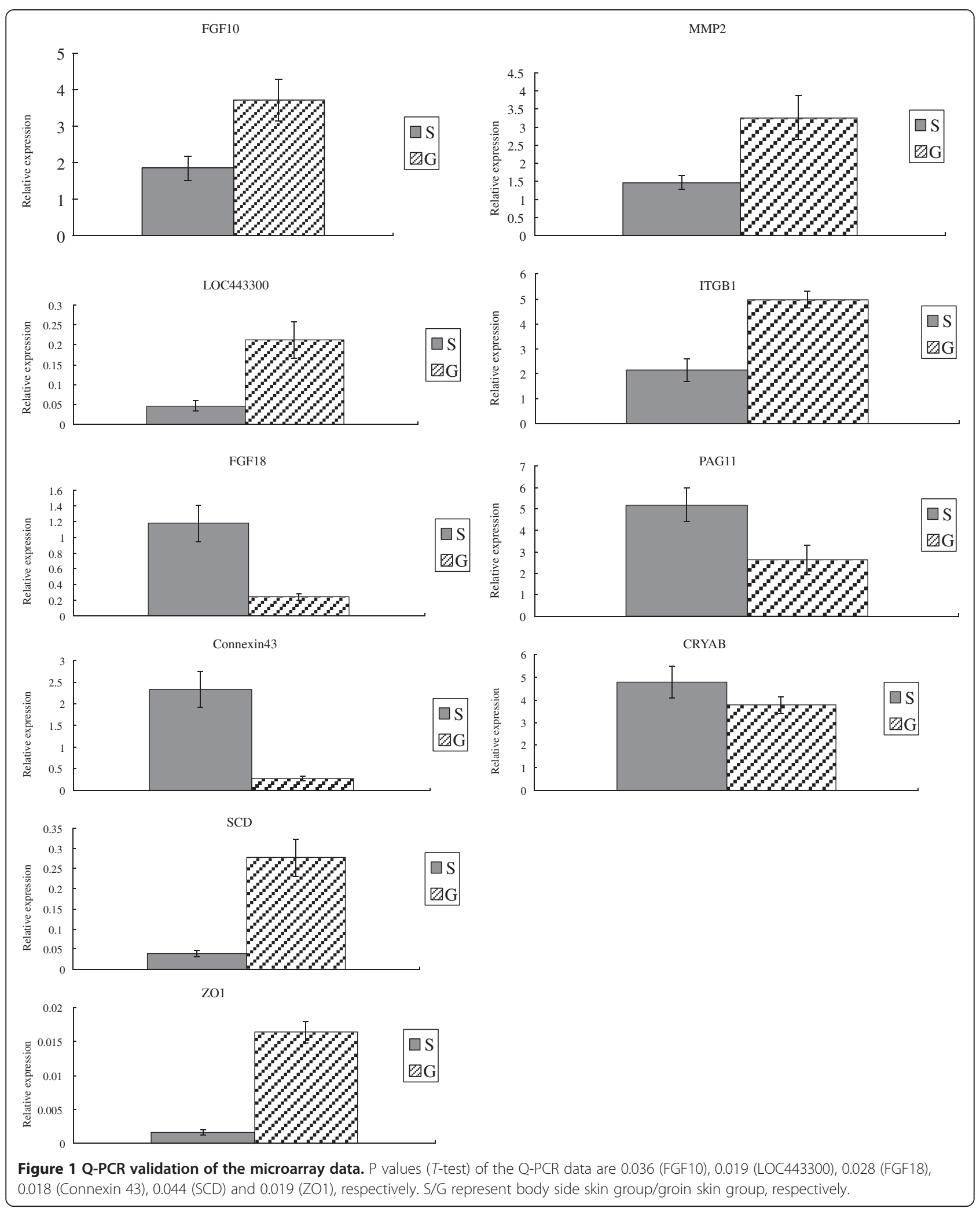


Figure 2 Hierarchical cluster analysis of data between different skin areas of the Aohan fine wool sheep in anagen phase. Each column represents one sheep, and each horizontal line refers to a gene. Color legend is on the top of the figure. Red indicates genes with a greater expression relative to the geometrical means, green indicates genes with a lower expression relative to the geometrical means. S1, S2 and S3 represent 3 repeats of body side skin group, and $G 1, G 2, G 3$ represent 3 repeats of groin skin group.

in body side skin as compared to the groin skin. Some of them could not be identified because of incomplete polypeptide fragments or low abundance (beyond the identification limit). In total, 46 protein entries were identified by MALDI-TOF/MS analyses. An overview of these proteins is presented in Additional file 4: Table S4.

\section{Discussion}

\section{Methodologies}

This study is a pilot to establish microarray methodologies in the wool growth field. Our results contrasted the gene expressed in the skin cells from hair-rich and hairless regions at transcriptional and translational levels. The number and fold-change of DE genes in December were much lower than that in August (5605 probes were differentially expressed in August; data not shown). That was compatible with reduced follicle activities in winter $[26,30]$. And most of DE genes in December were also differentially expressed in August (data not shown).

The advantage of this study is that samples could be obtained easily while the weakness of this study is the low specificity in the samples because the skin samples compose not only wool follicle, but also other parts of the skin.

\section{The limitations encountered during the study and how we determine the results}

The small sample size is another weakness of this study. These three animals used in the study were half sibs (sharing the same father). The number of our resource population was not very large, so it was difficult to select more than three even-aged half sibs. It is unusual using only three animals, but this shortcoming could be partly made up for through using genetically related animals. Additionally, to confirm the reliability of the results from the microarray experiments, we conduct the qPCR validation for the expression levels of selected 10 genes, whose fold-changes between the two skin areas ranged from 2.15 to 19.42 . Seven of these 10 genes displayed the same regulation directions compared to the microarray results, indicating our differential expression data had relatively reliable value in the field.

The technical approach (microarrays) is another limitation of the study. First, the number of the probes (15208) designed by Agilent is limited compared to the 


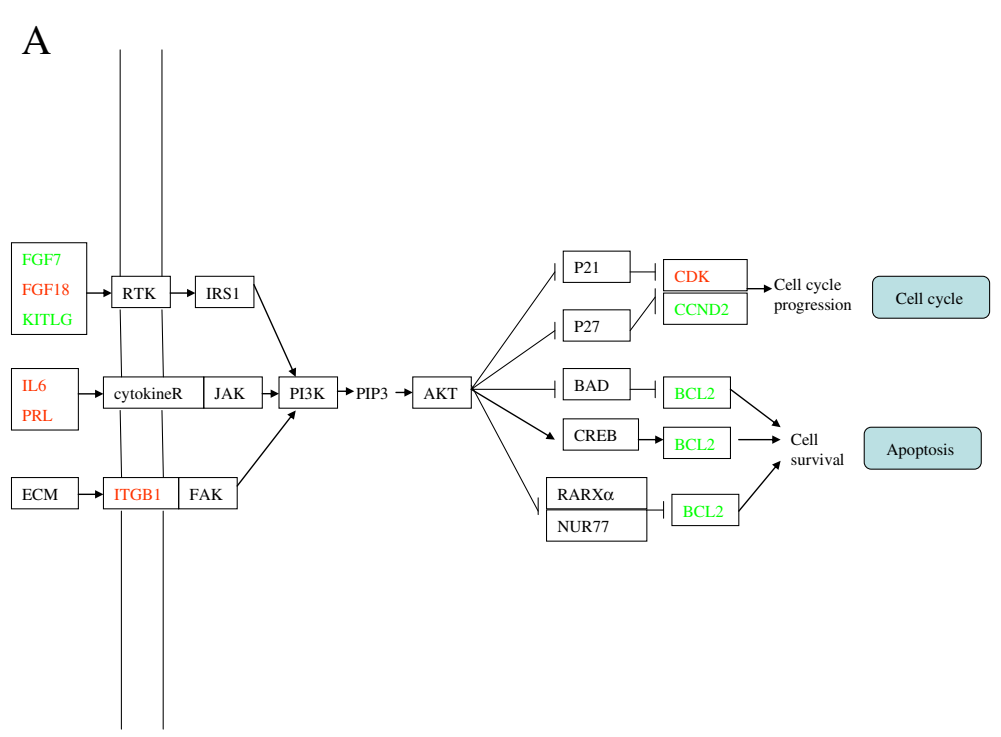

B

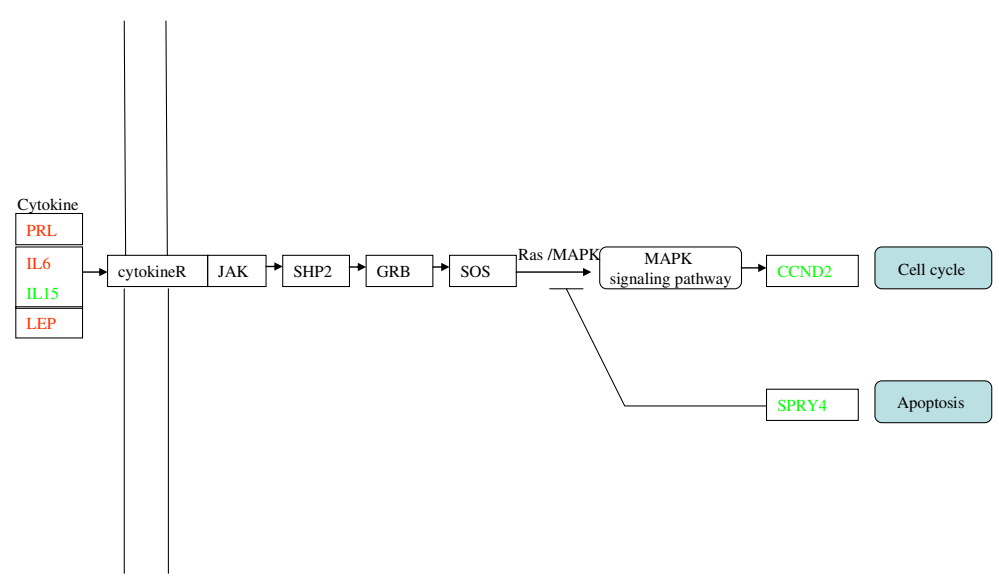

Figure 3 Biological pathways having more differentially expressed genes. A: PIBK-AKT Pathway; B: JAK-STAT Pathway. Gene name in red in the gene box indicates higher gene expression in $\mathbf{S} / G$, green indicates lower gene expression, and black indicates no change of the gene expression.

RNA-seq method [25]. Most of the probes were inadequately annotated. The full utility of the microarray data depends on the complete annotation of the whole sheep genome. Second, the specificity of the probes is relatively lower than RNA-sequencing, although using 60-mers long probes in our study. False positive and false negative phenomena exsit unavoidably in the microarray data.

\section{Functional implication of differentially expressed genes in the microarray study}

In the present study, we investigated the molecular events possibly related to sheep hair growth control using microarray and proteomic technologies. Transcriptomic analysis identified hundreds of differentially expressed genes displaying over 2-fold difference between the two sampled skin regions of Aohan fine wool sheep at December time point, and the number of less highly expressed transcripts (892) in body side skin was greater than that of the more highly expressed ones (602). The qPCR results validated the reliability of our microarray data.

IL-1A and IL-1B inhibit hair growth in vitro as reported previously [31], but IL-1A has shown downregulation in body side skin in our study. One possibility is in vivo IL-1A controls wool growth in a time dependent or a negative feedback manner.

The skin of skin-specific SCD1 knock-out (SKO) mice exhibited variable orthokeratotic hyperkeratosis and parakeratotic hyperkeratosis, occasional mal-aligned hair follicles, and instances of protrusion of hair shafts out of the hair follicle and into the surrounding connective tissue, with an infiltration of inflammatory cells surrounding the exposed hair shaft and keratin material [32]. In 
our study, SCD was less highly expressed at 11.91 fold change in body side skin. This maybe indicate that the $S C D$ could play an important role in groin skin.

MMP2 activity is associated with the disappearance of collagen VII during the invasion of epithelial cords of hair follicles and sweat glands in human skin [33]. $M M P 2$ plays a role in hair growth-associated extracellular matrix remodeling and cell migration, and may be a downstream effector through which thymosin $\$ 4$ exerts its effect on hair growth [34]. However, MMP2 showed significant lower expression in body side skin. This may suggest sheep has a different hair growth regulatory mechanism than human.

There is a log linear relationship between the relative level of beta 1 integrins (ITGB1) on the cell surface and proliferative capacity in keratinocytes [35]. ITGB1-mediated signalling is also important in human hair growth control [36]. Skin and hair follicle integrity is crucially dependent on ITGB1 expression in keratinocytes [37]. In our study, however,ITGB1 expression in the body side skin was less highly expressed. The mechanism how it happens deserves further investigation.

Rowe et al. confirmed that predominantly CYP1A1 was located to the sebaceous gland surrounding the hair shaft [38]. It is not known why CYP1A1 expression was less highly expressed more than 10 folds in the body side skin from our data. This interesting phenomenon is worth pursuing in future studies.

As development proceeds, GluD1 expression becomes restricted to the hippocampus, cochlear and vestibular hair cells, and spiral ganglion cells [39-41]. Hair follicles are also derived from ectoderm. So why GLUD1 was less highly expressed in body side skin really deserves further investigation.

Connexin 43 (Cx43) is a gap junction protein expressed in the follicular dermal papilla (DP) [42]. A recent mouse model research suggested an important role for $C \times 43$ in hair regeneration, growth, and cuticle formation [43]. However, Connexin 43 was less highly expressed in body side skin in the microarray analysis of this study, and it was also confirmed by qPCR.

Several papers indicated that prostaglandin induced hair growth $[44,45]$, but in our results, one prostaglandin synthase (PGFS) were less highly expressed in body side skin. This interesting contradiction remains to be further elucidated.

We have indeed tried our best to find out differentially expressed genes associated with LCE and MOGAT as reported in a Science paper [25]. However, we could find only a few genes (DGAT2, LPL, ZO1, GJB2 and ITGB1) 


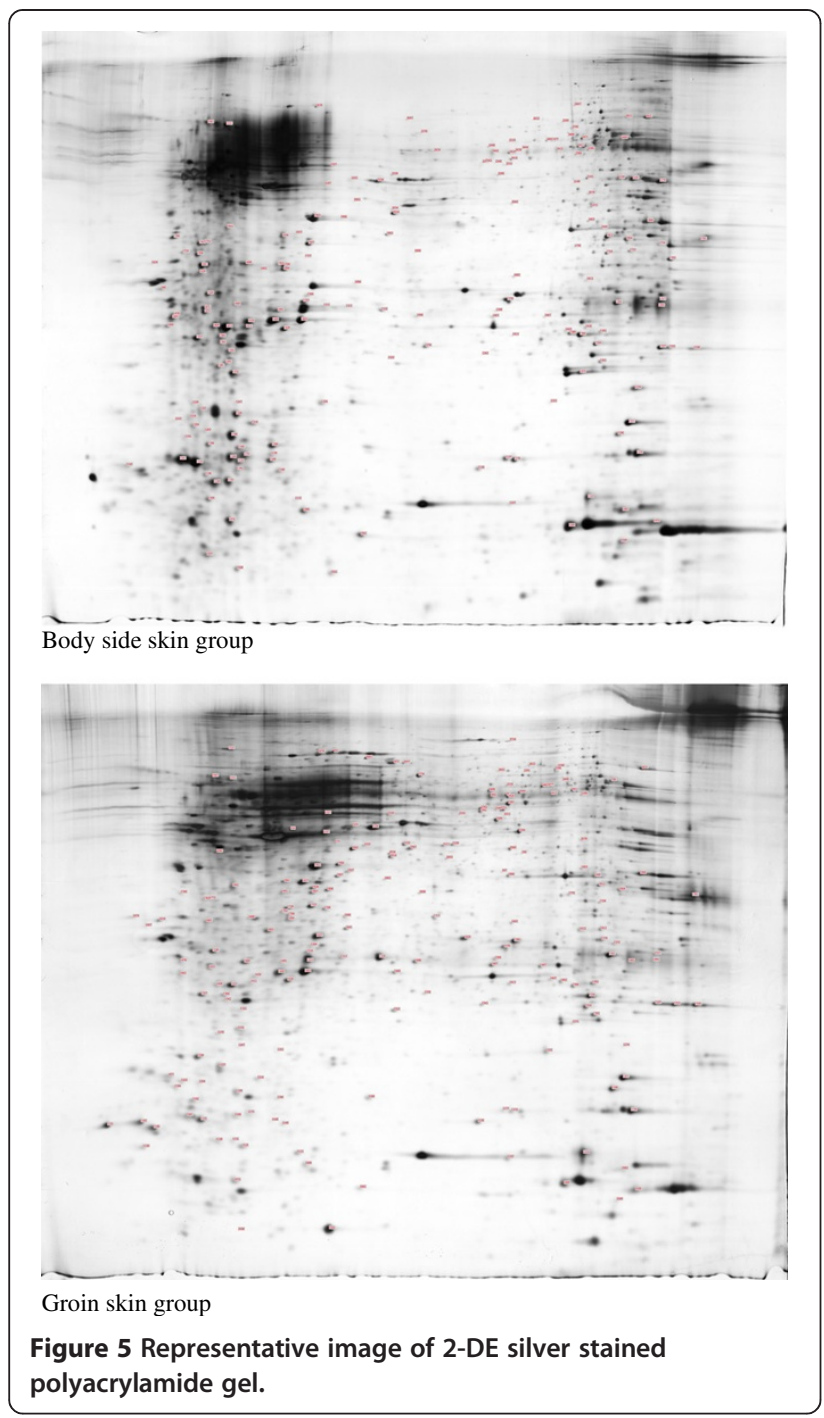

that have the possibility to play roles in epidermal development complex (EDC) or skin lipid metabolism. One reason for limited DE genes is that what we compared were different regions of sheep skin tissue (which might share similar principles in EDC regulation and lipid synthesis), not distinct tissues such as rumen and skin. That might also be caused by inadequate annotation of the probes or less gene coverage redundancy of the Agilent microarray.

Functional implication of differentially expressed proteins in the proteomic study

Most of the differentially expressed proteins were not listed above in the Discussion.

Cryab protein was detected in 2DE in groin skin but not in body side skin. But the Cryab transcripts was more highly expressed in body side skin by the microarray study, though the differential expression was not validated by qPCR. This gene, downregulated in the transcriptional level during the depilation-induced hair cycle [46], was considered to play a role in regulation of apoptosis.

FGF18 protein was less highly expressed in body side skin compared to the control. But the FGF18 transcripts was more highly expressed by the microarray study. Consistent to our microarray results, FGF18 is highly expressed in hair follicles and capable of inducing anagen from telogen stage hair follicles [30].

KRT14 and KRT2.11 proteins were both less highly expressed in body side skin compared to the control. But these proteins were expected to play roles in wool follicles [47-51].

PADI3 played roles in the assembly of a globular S100A3 homotetramer,a putative $\mathrm{Ca}^{2+}$ modulator maturing human hair cuticle [52]. But the PADI3 protein was less highly expressed in body side skin compared to the control in our study. This interesting contradiction remains to be further elucidated.

FGFR3 RNA was detected in precuticle cells in the periphery of the hair bulb $[53,54]$. But FGFR3 protein was less highly expressed in body side skin compared to the control in our study.

\section{Concordance between the results of transcriptomic and proteomic levels}

In the results of transcriptomic level (microarray), the number of more highly expressed genes was less than that of less highly expressed ones (602 versus 892 ). Consistently, more highly expressed protein spots were less than more lowly expressed ones (85 versus 102).

The concordance between these two results from microarray and proteomic experiments was shown in Additional file 4: Table S4. Of the 46 identified proteins, 13 corresponding transcripts also shown differential expression. Among these 13 transcripts, the regulation trends of only 6 (in green) were consistent with their protein counterparts. The inconsistency of the two levels of other $7 \mathrm{DE}$ genes (in red) might be produced by post transcriptional regulation or for unknown reasons.

\section{The confidence of the differentially expressed transcripts}

For the Agilent microarray, the probe number of each gene is indefinite, from 1 to 5 . There exists alternative splicing after gene transcription, so the inconsistency between different probes for the same gene is sometimes reasonable. Certainly the confidence is higher if all probes for the same gene were differentially expressed. For example, there are 4 probes for FGF7 and LOC443300(YWHAE) separately, of which 2 were both less highly expressed in $\mathrm{S} / \mathrm{G}$. So we speculated that the reliabilities of differential expression of FGF7 and LOC443300 were close to each other. While MMP2 differential expression was only 
detected in one of three probes, then its confidence might be lower than the former two genes (FGF7 and LOC443300). Nevertheless, because of the inadequate annotation of most probes, we found it difficult to calculate probe number of all the differentially expressed genes.

\section{Gene networks}

Figure 5 listed some of the factors which possibly play roles in wool growth regulation [29]. We speculate that lower temperature and shorter day photoperiod were key causes of the downregulation of wool growth rate. So we could speculate that those 8 genes (IL1A,FGF7, TAC1,IGFBP3,CDKN1B,IL6,FGF18 and PRL) played roles in wool growth regulation during winter.

\section{Conclusions}

In summary, the data presented in this study suggested that the body side skin displays a differentially expressed pattern in comparison with the groin skin at December time point. The majority of these genes possibly related to the wool growth control, and they could be assigned into the categories including regulation of receptor binding, multicellular organismal process, protein binding and macromolecular complex. Several potential gene families might participate in hair growth regulation, including fibroblast growth factors, transforming growth factor- $\beta$, insulin-like growth factor, and so on. Proteomic analysis also identified hundreds of differentially expressed proteins. This systematic analysis could lead to a better understanding of the wool growth control mechanism in Aohan fine wool sheep.

\section{Methods}

\section{Animals and sample preparation}

All animals were treated in accordance with the animal protocols defined by national and local animal welfare bodies, and all animal work was approved by the Shandong Province Biological Studies Animal Care and Use Committee.

Sampling methods were described previously $[25,26]$. One ram and two ewes of 16-month-old Aohan fine wool sheep were used in the microarray study. These animals were half sibs (sharing the same father). In December 2010, two areas of full-thickness skin were sampled from the same animal under local anaesthesia: body side skin (wool bearing) and groin skin (non-wool bearing) for microarray and proteomic experiments. The area of each sample was about $1 \mathrm{~cm}^{2}$. All samples were immediately put into collection tubes and stored in liquid nitrogen for RNA and protein extraction. A total of 15, 208 probes were spotted on this Agilent Sheep Gene Expression Microarray (Santa Clara, CA, USA).

\section{RNA extraction and microarray hybridization}

TRIzol (Invitrogen) was used for total RNA extractions according to the manufacturer's protocol. RNA quantity and quality were measured by NanoDrop ND-1000. Its OD260/OD280 ratio was confirmed to be higher than 1.8. RNA integrity was assessed by standard denaturing agarose gel electrophoresis. The RNA samples were sent to Kangchen Biotechnology Limited Company (Shanghai, China) for hybridization to the Agilent Sheep Gene Expression Microarray (Santa Clara, CA, USA). Each RNA sample was hybridized to one microarray slide. $1 \mu \mathrm{g}$ of total RNA from each sample was amplified and transcribed into fluorescent cRNA with using the manufacturer's Agilent's Quick Amp Labeling protocol (version 5.7, Agilent Technologies). The labeled cRNAs were hybridized onto the Whole Genome Oligo Array (4x44K, Agilent Technologies).

\section{Microarrays data analysis}

After hybridization and washing, the microarray slides were scanned with the Agilent Scanner G2505B. The resulting text files extracted from Agilent Feature Extraction Software (version 10.5.1.1) were imported into the Agilent GeneSpring GX software (version 11.0) for further analysis. Quantile normalization, probe annotation and subsequent data processing were performed using the GeneSpring GX v11.0 software package (Agilent Technologies). After Quantile normalization of the raw data, genes that at least 1 out of 6 samples have flags in Present ("All Targets Value") were chosen for differentially expressed genes screening. Gene expression levels were quantified relative to the expression of GAPDH. Differentially expressed genes were identified through foldchange screening. The fold-change of 2.0 and a false discovery rate of approximately $5 \%$ were set as the threshold. All data have been deposited in NCBI's Gene Expression Omnibus and are accessible through GEO Series accession number GSE62552 (http://www.ncbi.nlm.nih.gov/geo/query/acc. cgi?acc). Clustering analysis of all differentially expressed genes was performed using Cluster $3.0[55,56]$ to analyze the similarity in the expression patterns among different skin sites. The functional annotation of differentially expressed genes was performed by the DAVID (The Database for Annotation, Visualization and Integrated Discovery) gene annotation tool (http://david.abcc.ncifcrf.gov/) [57]. The KEGG pathway analysis was done manually (http://www.genome.jp/kegg/).

Particular differentially expressed genes, which also appeared in the Figure 1 of reference No. 29 summarizing selective factors with known hair growth regulatory roles [29], were included in the putative gene networks of wool growth regulation. The networks contained genes possibly playing roles in anagen promotion and maintenance, in catagen-telogen promotion and maintenance, or with function unknown. 


\section{QPCR}

The total RNA samples prepared for microarray analysis were also used for qPCR analysis. Reverse transcriptions were performed using RevertAid First Strand cDNA Synthesis Kit (MBI Fermentas, Vilnius, Lithuania) according to the manufacturer's protocols. The primers were designed with the Oligo 6.0 program. The primer sequences, melting temperatures and product sizes are shown in Table 1. Gene expression levels were quantified relative to the expression of GAPDH.

\section{Tissue protein extraction}

Lysis buffer preparation: 42\% Urea, 15.2\% Thiourea, 4\% CHAPS, 1\% DTT. Sampled tissues were homogenziated in lysis buffer (containing 1\% cocktail and 2\% IPG-buffer, added right before use) at the ratio of 1:7 (weight/volume). The tissues were cut into small pieces by ophthalmic scissors, and left at $4^{\circ} \mathrm{C}$ for $1 \mathrm{~h}$, vortexed it every $15 \mathrm{~min}$. Then, the tissue homogenate was centrifuge at 40,000 $\mathrm{g}$ for $30 \mathrm{~min}$. Supernatants were collected and stored at $-80^{\circ} \mathrm{C}$. Protein concerntrations were determined by Bradford method.

Table 1 Primers used for Q-PCR validation

\begin{tabular}{|c|c|c|c|}
\hline Gene & Primer sequence $\left(5^{\prime}-3^{\prime}\right)$ & $\operatorname{Tm}\left({ }^{\circ} \mathrm{C}\right)^{\mathrm{a}}$ & $\begin{array}{l}\text { Target } \\
\text { size (bp) }\end{array}$ \\
\hline \multirow[t]{2}{*}{$\mathrm{GAPDH}^{\mathrm{b}}$} & Forward: ATGCCTCCTGCACCACCA & 60 & 76 \\
\hline & Reverse: AGTCCCTCCACGATGCCAA & & \\
\hline \multirow[t]{2}{*}{ FGF10 } & Forward: GATCCGAGAAAGGAGCGAGG & 60 & 554 \\
\hline & Reverse: TCCAGGATACTGTACGGGCA & & \\
\hline \multirow[t]{2}{*}{ LOC443300 } & Forward: ACCAACACATCCCATTCGCT & 60 & 140 \\
\hline & Reverse: CACTCAGCGTGTCCAGTTCT & & \\
\hline \multirow[t]{2}{*}{ FGF18 } & Forward: AAGTCCGGATCAAGGGCAAG & 60 & 98 \\
\hline & Reverse: CACACACTCTITGCTGGTGC & & \\
\hline \multirow[t]{2}{*}{ Connexin43 } & Forward: GTCGTGTCGTTGGTGTCTCT & 60 & 291 \\
\hline & Reverse: CACTCAGCGTGTCCAGTTCT & & \\
\hline \multirow[t]{2}{*}{ SCD } & Forward: AAGAGTGGCTGAGTTTCTGGTC & 60 & 277 \\
\hline & Reverse: GAAAGGAAGGTGATAGGGACAA & & \\
\hline \multirow[t]{2}{*}{ Zo1 } & Forward: AGATAGCCCTGCAGCCAAAG & 60 & 117 \\
\hline & Reverse: GGGAGGTCAAGCAGGAAGAG & & \\
\hline \multirow[t]{2}{*}{ MMP2 } & Forward: AACGCCATCCCTGATAACCT & 60 & 126 \\
\hline & Reverse: GCTTCCGAACTTCACGCTC & & \\
\hline \multirow[t]{2}{*}{ ITGB1 } & Forward: AGCACGGATGAGGTGAACAG & 60 & 407 \\
\hline & Reverse: CCAAGGCAGGTCTGACACAT & & \\
\hline \multirow[t]{2}{*}{ PAG11 } & Forward: AGCGTCGCCTACGAATCTG & 60 & 120 \\
\hline & Reverse: CTCAAACCCATATTCCGTCACA & & \\
\hline \multirow[t]{2}{*}{ CRYAB } & Forward: CACCCAGCTGGATTGACACT & 60 & 147 \\
\hline & Reverse: CCTCATGTITGCCATGCACC & & \\
\hline
\end{tabular}

${ }^{a}$ The annealing temperature represents the optimal temperature during quantitative $P C R$

${ }^{\mathrm{b}} \mathrm{RNA}$ levels of GAPDH was assayed for normalization during quantitative PCR.

\section{One-dimensional electrophoresis}

0.5\% IPG-buffer was added into each $150 \mu \mathrm{g}$ protein sample (in a final volume of $400-600 \mu \mathrm{L}$ ), and was loaded in the One-dimensional electrophoresis instrument. The progamme is as follows: Step-n-hold (S1, $30 \mathrm{~V}$ for $6 \mathrm{~h}$; S2, $60 \mathrm{~V}$ for $6 \mathrm{~h}$ ); Gradient (S3, $500 \mathrm{~V}$ for $1 \mathrm{~h} ; \mathrm{S} 4,1000 \mathrm{~V}$ for $1 \mathrm{~h}$; S5, $3000 \mathrm{~V}$ for $3 \mathrm{~h}$; S6, $8000 \mathrm{~V}$ for $3 \mathrm{~h}$ ); Step-n-hold (S7, $8000 \mathrm{~V}$ for $20 \mathrm{~h}$ ).

\section{2-dimensional (2-D) SDS-PAGE preparation}

Tris-HCl $(\mathrm{PH}=8.8)$, Monomer storage (30\% Acrylamid and $0.8 \%$ NN'-methy lenebisacry lamid), $10 \times$ electrophoresis buffer (3.03\% Tris-Base, $14.4 \%$ Glycine, 1\% SDS), balanced solution (36.05\% Urea, 5\% Tris- $\mathrm{HCl}, 2 \%$ SDS, 34.5\% Glycerine).

\section{The second dimensional SDS-PAGE}

The electrophoresis programme is as follows:

Transfer: Voltage 300v, Current $50 \mathrm{~mA}$, Time $1 \mathrm{~h}$. Separation: Voltage 300v, Current $200 \sim 250 \mathrm{~mA}$, Time $4 \sim 5 \mathrm{~h}$.

Fixative preparation: 40\% Ethanol and 10\% Acetic acid. Electrophoresis was carried out until the blue dye front had just disappeared from the bottom of the gel.

Fixation: take out the rubber strip and put it into Fixative for $1 \mathrm{~h}$.

\section{Staining and visualization}

Sensitizing solution preparation: 30\% Ethanol, 0.314\% $\mathrm{Na}_{2} \mathrm{~S}_{2} \mathrm{O}_{3}, 6.8 \% \mathrm{NaAc}$.

Sensitizing: the gels were sensitized for $30 \mathrm{~min}$.

Washing: the gels were washed for three times using $\mathrm{ddH}_{2} \mathrm{O}$. Ten minutes each time.

Ilver staining: Silver staining solution was prepared (1.25

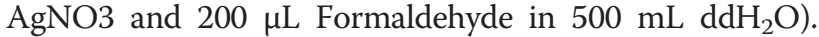
The gels were stained by the solution for $20 \mathrm{~min}$.

Washing: the gels were washed for 2 min using $\mathrm{ddH}_{2} \mathrm{O}$.

Visualizing solution preparation: $12.5 \mathrm{~g} \mathrm{Na}_{2} \mathrm{CO} 3$ and $100 \mu \mathrm{L}$ Formaldehyde in $500 \mathrm{~mL} \mathrm{ddH}_{2} \mathrm{O}$.

Termination solution preparation: $2 \mathrm{~g}$ Glycine in $50 \mathrm{ml}$ ddH2O.

Visualization until the solution became muddy, then terminating for $30 \mathrm{~min}$.

\section{Determination of relative protein expression}

Gels were then scanned and analyzed using ImageMaster TM 2D platinum software (Version 5.0, GE Healthcare, San Francisco, CA, USA). The expression level was determined by the relative volume of each spot in the gel and expressed as \% Vol (\% Vol $=[$ spot volume/ ¿volumes of all spots resolved in the gel]). The means and standard deviations of both sample groups were calculated. Statistical significance with Student's t-tests using 
ImageMaster TM 2D platinum software. $\mathrm{P}$ values $<0.05$ were considered statistically significant.

\section{Identification of differentially expressed proteins by mass spectrometry (MS)}

Protein spots with significant differences between the two groups were excised, dehydrated in acetonitrile, and dried at room temperature. Gel pieces were denatured, alkylated, trypsin digested and analyzed by an Ultraflex II MALDITOF-TOF mass spectrometer (Bruker Daltonics GmbH, Bremen, Germany) under the control of FlexControl TM 2.4 software (Bruker Daltonics GmbH). Acquired peptide mass fingerprint (PMF) were processed using the software FlexAnalysis $^{\mathrm{sm}}$ 3.0 (Bruker Daltonics, Bremen, Germany). The peak detection algorithm was: SNAP (Sort Neaten Assign and Place); S/N threshold: 1.5; Quality Factor Threshold: 50. The tryptic auto-digestion ion picks (trypsin [108-115] 842.5094 Da, trypsin [58-77] 2211.104 Da) were used as internal standards. The resulting peptide mass lists were used to search the Matrixscience database (http:// www.matrixscience.com). The following search parameter criteria were used: mass tolerance $100 \mathrm{ppm}$, miss cleavage $\leqq 1$, modification comprises carbamidomethyl and methionine oxidation. Matched peptides number between experimental $\mathrm{PMF}$ and theoretical $\mathrm{PMF} \geqq 5$ [58]. All MS data have been deposited in PeptideAtlas and are accessible through Dataset Identifier PASS00597 (http://www.peptideatlas.org/PASS/PASS00597).

\section{Availability of supporting data}

All cDNA microarray data have been deposited in NCBI's Gene Expression Omnibus and are accessible through GEO Series accession number GSE62552 (http://www. ncbi.nlm.nih.gov/geo/query/acc.cgi?acc=GSE62552).

Proteomic data have been deposited in PeptideAtlas and are accessible through Dataset Identifier PASS00597 (http://www.peptideatlas.org/PASS/PASS00597).

\section{Additional files}

Additional file 1: Table S1. Differentially expressed genes.

Additional file 2: Table S3. DE genes and their relation to different aspects of hair follicle growth.

Additional file 3: Table S2. Gene Ontology analysis.

Additional file 4: Table S4. Differentially expressed proteins.

\section{Competing interests}

The authors declare that they have no competing interests.

\section{Authors' contributions}

JZ and HL carried out data collection and analysis and manuscript preparation. KL carried out data analysis. JY participated in data analysis. MC, participated in data collection. WD participated in data discussion and manuscript preparation. RB participated in manuscript preparation. $J L$ and $\mathrm{GH}$ participated in discussion of the study. NL participated in the design of the study, coordination, data analysis and manuscript preparation. All authors read and approved the final manuscript.

\section{Acknowledgments}

We are very grateful to Prof. Yinlin Ge for technical assistance. This research was supported by the Project of National Hair Sheep Industry Technology System (CARS-40), the Projects of Qingdao People's Livelihood Science and Technology (13-1-3-88-nsh;14-2-3-45-nsh), and Open Research Fund Program of State key Laboratory of Hydroscience and Engineering (sklhse-2012-D-02).

\section{Author details}

${ }^{1}$ Qingdao Agricultural University, Qingdao 266109, China. ${ }^{2}$ Qingdao Institute of Animal Science and Veterinary Medicine, Qingdao 266100, China. ${ }^{3}$ China Agricultural University, Beijing 100193, China. ${ }^{4}$ Nanjing Medical University, Nanjing 210002, China. ${ }^{5}$ State key Laboratory of Hydroscience and Engineering, Beijing 100084, China.

Received: 19 November 2013 Accepted: 3 December 2014

Published online: 16 December 2014

\section{References}

1. Purvis IW, Franklin IR: Major genes and QTL influencing wool production and quality: a review. Genet Sel Evol 2005, 37(S1):S97-S107.

2. Beh KJ, Callaghan MJ, Leish Z, Hulme DJ, Lenane I, Maddox JF: A genome scan for QTL affecting fleece and wool traits in Merino sheep. Wool Technol Sheep Breed 2001, 49:88-89.

3. Bidinost F, Roldan DL, Dodero AM, Cano EM, Taddeo HR, Mueller JP, Poli MA: Wool quantitative trait loci in Merino sheep. Small Ruminant Res 2008, 74:113-118.

4. Cano EM, Marrube G, Roldan DL, Bidinost F, Abad M, Allain D, Vaiman D, Taddeo H, Poli MA, Bray AR: QTL affecting fleece traits in Angora goats. Small Ruminant Res 2007, 71:158-164.

5. Itenge TO, Hickford JG, Forrest RH, McKenzie GW, Frampton CM: Improving the quality of wool through the use of gene markers. South Afr J Animal Sci 2009, 39:219-223.

6. Galbraith H: Fundamental hair follicle biology and fine fibre production in animals. Animal 2010, 4:1490-1509.

7. Schmidt-Ullrich R, Paus R: Molecular principles of hair follicle induction and morphogenesis. Bioessays 2005, 27:247-261.

8. McGrice HA: Molecular Characterisation of Primary Wool Follicle Initiation in Merino Sheep, PhD thesis. University of Adelaide, School of agriculture, food and wine; 2010

9. Janich P, Pascual G, Merlos-Suarez A, Batlle E, Ripperger J, Albrecht U, Obrietan K, Di Croce L, Benitah SA: The circadian molecular clock creates epidermal stem cell heterogeneity. Nature 2011, 480:209-214.

10. Rhee H, Polak L, Fuchs E: Lhx2 maintains stem cell character in hair follicles. Science 2006, 312:1946-1949.

11. Cotsarelis G: Gene expression profiling gets to the root of human hair follicle stem cells. J Clin Invest 2006, 116:19-22.

12. Ohyama M, Terunuma A, Tock CL, Radonovich MF, Pise-Masison CA, Hopping SB, Brady JN, Udey MC, Vogel JC: Characterization and isolation of stem cell-enriched human hair follicle bulge cells. J Clin Invest 2006, $116: 249-260$.

13. Keane OM, Zadissa A, Wilson T, Hyndman DL, Greer GJ, Baird DB, McCulloch AF, Crawford AM, McEwan JC: Gene expression profiling of naive sheep genetically resistant and susceptible to gastrointestinal nematodes. BMC Genomics 2006, 7:42.

14. MacKinnon KM, Burton JL, Zajac AM, Notter DR: Microarray analysis reveals difference in gene expression profiles of hair and wool sheep infected with Haemonchus contortus. Vet Immunol Immunopathol 2009, 130:210-220.

15. Bongiorni S, Chillemi G, Prosperini G, Bueno S, Valentini A, Pariset L: A tool for sheep product quality: custom microarrays from public databases. Nutrients 2009, 1:235-250.

16. Faucon F, Rebours E, Bevilacqua C, Helbling JC, Aubert J, Makhzami S, Dhorne-Pollet S, Robin S, Martin P: Terminal differentiation of goat mammary tissue during pregnancy requires the expression of genes involved in immune functions. Physiol Genomics 2009, 40:61-82.

17. Ollier S, Robert-Granie C, Bernard L, Chilliard Y, Leroux C: Mammary transcriptome analysis of food-deprived lactating goats highlights genes involved in milk secretion and programmed cell death. J Nutr 2007, 137:560-567. 
18. Norris BJ, Bower NI, Smith WJ, Cam GR, Reverter A: Gene expression profiling of ovine skin and wool follicle development using a combined ovine-bovine skin cDNA microarray. Aust J Exp Agr 2005, 45:867-877.

19. Smith WJ, Li Y, Ingham A, Collis E, MCWilliam SM, Dixon TJ, Norris BJ, Mortimer SI, Moore RJ, Reverter A: A genomics-informed, SNP association study reveals FBLN1 and FABP4 as contributing to resistance to fleece rot in Australian Merino sheep. BMC Vet Res 2010, 6:27.

20. Penagaricano F, Zorrilla P, Naya H, Robello C, Urioste Jl: Gene expression analysis identifies new candidate genes associated with the development of black skin spots in Corriedale sheep. J App/ Genet 2012, 53:99-106.

21. Wenguang $Z$, Jianghong $W$, Jinquan $L$, Yashizawa $M$ : A subset of skin-expressed microRNAs with possible roles in goat and sheep hair growth based on expression profiling of mammalian microRNAs. OMICS 2007, 11:385-396.

22. Yu Z-D, Bawden CS, Henderson HV, Nixon AJ, Gordon SW, Pearson AJ: Micro-arrays as a discovery tool for wool genomics. Proc New Zeal SocAnimal Prod 2006, 66:129-133.

23. Yu Z-D, Gordon SW, Pearson AJ, Henderson HV, Craven AJ, Nixon AJ: Gene expression profiling of wool follicle growth cycles by cDNA microarray. Proc New Zeal SocAnimal Prod 2008, 68:39-42.

24. Liu N, Li H, Liu K, Yu J, Cheng M, De W, Liu J, Shi S, He Y, Zhao J: Differential expression of genes and proteins associated with wool follicle cycling. Mol Biol Rep 2014, published online in advance of the print edition.

25. Jiang $Y$, Xie M, Chen W, Talbot R, Maddox JF, Faraut T, Wu C, Muzny DM, Li Y, Zhang W, Stanton JA, Brauning R, Barris WC, Hourlier T, Aken BL, Searle SM, Adelson DL, Bian C, Cam GR, Chen Y, Cheng S, DeSilva U, Dixen K, Dong Y, Fan G, Franklin IR, Fu S, Fuentes-Utrilla P, Guan R, Highland MA, et al: The sheep genome illuminates biology of the rumen and lipid metabolism. Science 2014, 344(6188):1168-1173.

26. Wang HR, Feng ZC, Du M, Ren JK, Li HR: Initial research for seasonal variation of wool growth of Aohan fine wool sheep. Inner Mongolia Animal Sci 1994, 3:1-3 (in Chinese).

27. Yu JJ, Liu JF, Zhao JS, Cheng M, Liu KD, Liu N: Gene chip analysis of expression pattern of type I Inner Root Sheath (IRS) keratin in AoHan wool sheep. Agr Scie Technol 2012, 13:1171-1174.

28. Zhao JS, Li HG, Liu KD, Liu N, Li JQ: Differential expression of immune genes between body side skin and groin skin of Aohan fine wool sheep. Agr Scie Technol 2012, 13:2475-2479.

29. McElwee KJ, Sinclair R: Hair Physiology and its Disorders. Drug Discovery Today: Disease Mechanisms. ; 2008:e163-e171.

30. Kawano M, Komi-Kuramochi A: Comprehensive analysis of FGF and FGFR expression in skin. J Invest Dermatol 2005, 124:877-885.

31. Stenn KS, Paus R: Controls of hair follicle cycling. Physiol Rev 2001, 81:449-494.

32. Sampath H, Flowers MT, Liu X, Paton CM, Sullivan R, Chu K, Zhao M, Ntambi JM: Skin-specific deletion of stearoyl-CoA desaturase-1 alters skin lipid composition and protects mice from high fat diet-induced obesity. J Biol Chem 2009, 284:19961-19973.

33. Karelina TV, Bannikov GA, Eisen AZ: Basement membrane zone remodeling during appendageal development in human fetal skin: the absence of type VII collagen is associated with gelatinase-A (MMP2) activity. J Invest Dermatol 2000, 114:371-375.

34. Philp D, Nguyen M, Scheremeta B, St-Surin S, Villa AM, Orgel A, Kleinman $H K$, Elkin M: Thymosin beta4 increases hair growth by activation of hair follicle stem cells. FASEB J 2004, 18:385-387.

35. Jones PH, Watt FM: Separation of human epidermal stem cells from transit amplifying cells on the basis of differences in integrin function and expression. Cell 1993, 73:713-724.

36. Kloepper JE, Hendrix S, Bodo E, Tiede S, Humphries MJ, Philpott MP, Fassler $R$, Paus R: Functional role of beta 1 integrin-mediated signalling in the human hair follicle. Exp Cell Res 2008, 314:498-508.

37. Brakebusch C, Grose R, Quondamatteo F, Ramirez A, Jorcano JL, Pirro A, Svensson M, Herken R, Sasaki T, Timpl R, Werner S, Fassler R: Skin and hair follicle integrity is crucially dependent on beta 1 integrin expression on keratinocytes. EMBO J 2000, 19:3990-4003.

38. Rowe JM, Welsh C, Pena RN, Wolf CR, Brown K, Whitelaw CB: Illuminating role of CYP1A1 in skin function. J Invest Dermatol 2008, 128:1866-1868.

39. Ryu K, Yokoyama M, Yamashita M, Hirano T: Induction of excitatory and inhibitory presynaptic differentiation by GluD1. Biochem Biophys Res Commun 2012, 417:157-161.
40. Lein ES, Hawrylycz MJ, Ao N, Ayres M, Bensinger A, Bernard A, Boe AF, Boguski MS, Brockway KS, Byrnes EJ, Chen L, Chen TM, Chin MC, Chong J, Crook BE, Czaplinska A, Dang CN, Datta S, Dee NR, Desaki AL, Desta T, Diep E, Dolbeare TA, Donelan MJ, Dong HW, Dougherty JG, Duncan BJ, Ebbert AJ, Eichele G, Estin LK, et al: Genome-wide atlas of gene expression in the adult mouse brain. Nature 2007, 445:168-176.

41. Magdaleno S, Jensen P, Brumwell CL, Seal A, Lehman K, Asbury A, Cheung T, Cornelius T, Batten DM, Eden C, Norland SM, Rice DS, Dosooye N, Shakya S, Mehta P, Curran T: BGEM: an in situ hybridization database of gene expression in the embryonic and adult mouse nervous system. PLOS Biol 2006, 4:e86.

42. Higgins CA, Richardson GD, Ferdinando D, Westgate GE, Jahoda CA: Modelling the hair follicle dermal papilla using spheroid cell cultures. Exp Dermatol 2010, 19:546-548.

43. Churko JM, Chan J, Shao Q, Laird DW: The G60S connexin43 mutant regulates hair growth and hair fiber morphology in a mouse model of human oculodentodigital dysplasia. J Invest Dermatol 2011, 131:2197-2204.

44. Colombe L, Vindrios A, Michelet JF, Bernard BA: Prostaglandin metabolism in human hair follicle. Exp Dermatol 2007, 16:762-769.

45. Johnstone MA, Albert DM: Prostaglandin-induced hair growth. Surv Ophthalmol 2002, 47(S1):S185-S202.

46. Umeda-lkawa A: Time-course expression profiles of hair cycle-associated genes in male mini rats after depilation of telogen-phase hairs. Int J Mol Sci 2009, 10:1967-1977.

47. Powell BC, Beltrame JS: Characterization of a hair (wool) keratin intermediate filament gene domain. J Invest Dermatol 1994, 102:171-177.

48. Yu Z, Gordon SW, Nixon AJ, Bawden CS, Rogers MA, Wildermoth JE, Magbool NJ, Pearson AJ: Expression patterns of keratin intermediate filament and keratin associated protein genes in wool follicles. Differentiation 2009, 77:307-316.

49. Goh BK, Common JE, Gan WH, Kumarasinghe P: A case of dermatopathia pigmentosa reticularis with wiry scalp hair and digital fibromatosis resulting from a recurrent KRT14 mutation. Clin Exp Dermatol 2009, 34:340-343.

50. Lugassy J, Itin P, Ishida-Yamamoto A, Holland K, Huson S, Geiger D, Hennies HC, Margarita I, Dani B, Jouni U, Bergman R, McGrath JA, Richard G, Sprecher E: Naegeli-Franceschetti-Jadassohn syndrome and dermatopathia pigmentosa reticularis: two allelic ectodermal dysplasias caused by dominant mutations in KRT14. Am J Hum Genet 2006, 79:724-730.

51. Horner ME, Parkinson KE, Kaye V, Lynch PJ: Dowling-Degos disease involving the vulva and back: case report and review of the literature. Dermatol Online J 2011, 17:1.

52. Kizawa K, Takahara H, Troxler H, Kleinert P, Mochida U, Heizmann CW: Specific citrullination causes assembly of a globular S100A3 homotetramer: a putative $\mathrm{Ca} 2+$ modulator matures human hair cuticle. J Biol Chem 2008, 283:5004-5013.

53. Lueking A, Huber O, Wirths C, Schulte K, Stieler KM, Blume-Peytavi U, Kowald A, Hensel-Wiegel K, Tauber R, Lehrach H, Meyer HE, Cahill DJ: Profiling of alopecia areata autoantigens based on protein microarray technology. Mol Cell Proteomics 2005, 4:1382-1390.

54. Rosenquist TA, Martin GR: Fibroblast growth factor signalling in the hair growth cycle: expression of the fibroblast growth factor receptor and ligand genes in the murine hair follicle. Dev Dyn 1996, 205:379-386.

55. Nacht M, Dracheva T, Gao Y, Fujii T, Chen Y, Player A, Akmaev V, Cook B, Dufault M, Zhang M, Zhang W, Guo M, Curran J, Han S, Sidransky D, Buetow $\mathrm{K}$, Madden SL, Jen J: Molecular characteristics of non-small cell lung cancer. Proc Natl Acad Sci U S A 2001, 98:15203-15208.

56. Tang Z, Li Y, Wan P, Li X, Zhao S, Liu B, Fan B, Zhu M, Yu M, Li K: LongSAGE analysis of skeletal muscle at three prenatal stages in Tongcheng and Landrace pigs. Genome Biol 2007, 8:R115.

57. Dennis G Jr, Sherman BT, Hosack DA, Yang J, Gao W, Lane HC, Lempicki RA: DAVID: database for annotation, visualization, and integrated discovery. Genome Biol 2003, 4:P3.

58. Berndt $\mathrm{P}$, Hobohm U, Langen $\mathrm{H}$ : Reliable automatic protein identification from matrix-assisted laser desorption/ionization mass spectrometric peptide fingerprints. Electrophoresis 1999, 20:3521-3526.

doi:10.1186/s12863-014-0144-1

Cite this article as: Liu et al: Identification of skin-expressed genes possibly associated with wool growth regulation of Aohan fine wool sheep. BMC Genetics 2014 15:144. 